\title{
History and Productivity Determine the Spatial Distribution of Key Habitats for Biodiversity in Norwegian Forest Landscapes
}

\author{
Magne Sætersdal ${ }^{1}$ *, Ivar Gjerde ${ }^{1}$, Einar Heegaard ${ }^{1}$, Fride Høistad Schei ${ }^{1}$ and \\ Jan Erik Ornelund Nilsen 2,3 \\ Received: 4 September 2015; Accepted: 21 December 2015; Published: 2 January 2016 \\ Academic Editors: Brian J. Palik and Eric J. Jokela \\ 1 Norwegian Institute of Bioeconomy Research, Fanaflaten 4, NO-5244 Fana, Norway; gji@nibio.no (I.G.); \\ ehe@nibio.no (E.H.); hof@nibio.no (F.H.S.) \\ 2 Norwegian Institute of Bioeconomy Research, Raveien 9, NO-1431 Ås, Norway; \\ jan.erik.nilsen@landbruksdirektoratet.no \\ 3 Norwegian Agricultural Agency, P.O. Box 8140 Department, NO-0033 Oslo, Norway \\ * Correspondence: sem@nibio.no; Tel.: +47-9366-2867
}

\begin{abstract}
Retention forestry, including the retention of woodland key habitats (WKH) at the forest stand scale, has become an essential management practice in boreal forests. Here, we investigate the spatial distribution of 9470 habitat patches, mapped according to the Complementary Habitat Inventory method (CHI habitats), as potential WKHs in 10 sample areas in Norway. We ask whether there are parts of the forest landscapes that have consistently low or high density of $\mathrm{CHI}$ habitats compared to the surveyed landscape as a whole, and therefore have a low or high degree of conflict with harvesting, respectively. We found that there was a general pattern of clumped distribution of $\mathrm{CHI}$ habitats at distances up to a few kilometres. Furthermore, results showed that most types of $\mathrm{CHI}$ habitats were approximately two to three times as common in the $25 \%$ steepest slopes, lowest altitudes and highest site indices. $\mathrm{CHI}$ habitats that are most common in old-growth forests were found at longer distances from roads, whereas habitats rich in deciduous trees were found at shorter distances from roads than expected. Both environmental factors and the history of human impact are needed to explain the spatial distribution of $\mathrm{CHI}$ habitats. The overrepresentation of WKHs in parts of the forest landscapes represents a good starting point to develop more efficient inventory methods.
\end{abstract}

Keywords: woodland key habitats; spatial distribution; forest landscapes; forestry; steep terrain; productivity; distance to road

\section{Introduction}

Globally, forest area reduction and degradation are among the most important factors threatening biodiversity. Approximately 14 million hectares of forest are annually lost to agriculture and other land uses [1]. Forests amount to 30\% of global terrestrial land area, and up to three quarters of terrestrial species are found in forests [2]. It is therefore of vital importance to the conservation of biodiversity that forests are managed in a sustainable way. Traditionally, conservation actions in forests were primarily to set aside forest areas as protected land. However, to date, this constitutes only $13 \%$ of global forest area, which is not supposed to be sufficient to stop the loss of biodiversity [1]. In recognition of this, we have seen the development of approaches where environmental, economic, and cultural values are managed on the same areas simultaneously [3]. Production of ecological and economic values in the same areas is challenging because of conflicts that potentially exist between these two objectives. 
A key question here is to what degree general patterns of biodiversity co-vary with general patterns of economic values such as harvesting.

At the landscape scale, there are several factors which are important for patterns of species richness. First, species richness is found to vary along altitudinal gradients [4]. Often a mid-elevation peak in species richness is found [5]. However, some studies find a linear decrease with altitude [6]. Different groups of organisms often show different patterns [7], as a result of variation in important factors causing the observed patterns. Second, there is a relationship between species richness and productivity [8]. This relationship is found to take different forms, depending on spatial scale [9]. However, in a study of the productivity-diversity relationships for several groups of organisms in six Norwegian forests, at a grain size of 0.25 ha forest plots, Gjerde et al. [10] found a general pattern of increasing species richness with productivity. Third, the intermediate disturbance hypothesis states that species richness tends to peak at intermediate levels of disturbance [11].

An important aspect of these factors is that they not only affect species richness but also the profits of the forest owner. The general patterns are that harvesting revenue decreases with altitude as a result of climatic variation, increases with increasing productivity, and decreases with increasing levels of disturbance. As a result of this potential co-variation between species richness and forest revenue, it is important to investigate the spatial distribution of these parameters to better understand the relationship between them.

As the world enters the transition towards a more sustainable bioeconomy, it is assumed that it is possible to improve the environmental measures at the same time as harvesting is increased. There are at least two major strategies (not mutually exclusive) to achieve this goal in managed forests [12]. The first involves harvesting systems based on the retention of structural elements or habitat types from the harvested stands, while the second strategy involves the retention of whole forest stands with high biodiversity values. In particular, retention forestry has become a very promising management approach. Retention forestry aims at maintaining important biological and physical elements of a harvested forest stand, such as dead wood and old trees, to ensure the long-term presence of both structures and organisms [12]. The retention practice originated from and has become an essential management practice in boreal forests $[3,12,13]$. In northern Europe, the retention practice in forestry is widely applied, including also the concept of woodland key habitat (WKH) (e.g., [14]). WKHs are small forest patches (mean size between 0.7 and 4.6 ha in different countries) considered to be of particular importance to forest biodiversity that are retained during final felling.

Given knowledge about the spatial distribution of stands with high or low biodiversity value, it is possible to avoid harvesting in areas with high biodiversity values and give preference to harvesting operations in areas with low value for biodiversity. In this study, we utilise Norwegian inventories to analyse the spatial distribution of different types of habitats. First, we investigate to what degree the habitats are spatially aggregated at different spatial scales using Ripley's K analyses. Secondly, we ask the question whether there are parts of the forest landscapes, in relation to the landscape parameters altitude, site index (productivity), distance from road, and slope, that have a consistently low or high density of habitat types important for red-listed species compared to all productive forest or to all mature forest, and therefore are well suited or less suited for future harvesting, respectively. The existence of consistent spatial patterns is also of great significance for the potential to develop more efficient inventory methods. By concentrating detailed field inventories on the parts of the landscape where there is a high probability of identifying important habitats and avoiding parts of the landscape where there is a low probability of finding important habitats, inventory costs can be reduced.

\section{Materials and Methods}

\subsection{Study System}

The forests of Norway are at the western border of the boreal forest zone. The two main commercial tree species are Norway spruce (Picea abies) and Scots pine (Pinus sylvestris) which constitute 
approximately one third of the forest area each. Boreal deciduous forest, such as aspen (Populus tremula) and birch (Betula pubescens), constitutes the last third of the forest area in Norway. In the boreo-nemoral zone in the south of Norway, several broadleaved deciduous tree species form deciduous forests on south facing slopes. However, these forests amount to only $1.3 \%$ of the productive forest area in Norway [15].

We used a geo-database containing areas mapped using the CHI habitat inventory method [16], to investigate which parts of Norwegian forest landscapes that have high and low probability of supporting different habitat types important for red-listed species at the forest stand scale. We selected four landscape variables which both reflect potential forest revenue and at the same time reflect one of the important factors of species richness variation, namely disturbance, productivity or altitude. The first two variables are slope and distance from road which both are related to disturbance. Increasing slope reflects increasing probability of natural disturbances such as screes and avalanches, whereas distance from road is reflecting decreasing human disturbance, such as due to forestry. Site index is a variable reflecting productivity (expressed as an index indicating height of 40-year old trees). Finally, mean altitude of the CHI habitat simply represents altitudinal variation. By analysing and comparing the distribution of habitats in 10 different landscapes (municipalities) we were able to detect local patterns as well as general patterns.

The CHI habitats (termed habitats hereafter) are mapped by forest planners in the field and the information is used when making forest management plans within each municipality. Twelve main habitat types are included in the inventory (Table 1), and they are delimited in the field according to specified criteria, either by using densities of habitat elements or by using vegetation or topographic criteria. An area is delimited on the map according to given threshold values for density and quality of habitats with size exceeding 0.2 hectares. The 12 forest habitat types were included in the inventory because they are inhabited by relatively large numbers of rare and threatened species, mainly the numerous species with small individual area demands [16]. Such species are to a large degree associated with habitats that are either less common in managed forests than in old-growth forests (Snags, Logs, Late successions of deciduous trees, Trees with pendant lichens, Old trees, Hollow deciduous trees, and Recently burned forest), highly nutritious forest habitats (Luxuriant ground vegetation, Trees with nutrient-rich bark), or highly humid forest habitats (north-facing Rock walls, Clay ravines, and Stream gorges). Nationally, approximately 110,000 habitat units have been mapped so far, and more than 70,000 of them have been set aside as WKHs, often including a buffer zone.

Table 1. The number of different CHI (Complementary Habitat Inventory) habitats recorded in 10 municipalities. A-H = Aurskog-Høland, $\mathrm{U}=$ Ullensaker, $\mathrm{M}=$ Marnardal, So = Songdalen, Sø = Søgne, $\mathrm{E}=$ Etnedal, $\mathrm{S}-\mathrm{A}=$ Sør-Aurdal, $\mathrm{T}=$ Tokke, $\mathrm{R}=$ Rendalen, $\mathrm{V}=$ Vinje. Late succ $=$ Late succession of deciduous trees, Pend lichen $=$ Pendant lichens, Lux ground $=$ Luxuriant ground vegetation, Rich bark = Trees with nutrient-rich bark.

\begin{tabular}{ccccccccccc}
\hline & \multicolumn{10}{c}{ Municipality } \\
\hline Habitat & A-H & $\mathbf{U}$ & $\mathbf{M}$ & So & Sø & E & S-A & T & R & V \\
\hline Snags & 7 & 3 & 7 & 4 & 0 & 18 & 84 & 2 & 56 & 13 \\
Logs & 145 & 22 & 261 & 102 & 185 & 92 & 458 & 442 & 197 & 167 \\
Late succ & 200 & 22 & 315 & 162 & 71 & 56 & 54 & 59 & 149 & 26 \\
Pend lichen & 1 & 0 & 3 & 0 & 0 & 21 & 299 & 4 & 16 & 3 \\
Old trees & 329 & 4 & 258 & 104 & 121 & 61 & 406 & 96 & 80 & 286 \\
Hollow trees & 7 & 0 & 0 & 0 & 0 & 0 & 0 & 0 & 0 & 0 \\
Recently burned & 0 & 0 & 0 & 0 & 6 & 0 & 0 & 0 & 0 & 0 \\
Lux ground & 251 & 33 & 318 & 273 & 396 & 337 & 140 & 729 & 109 & 87 \\
Rich bark & 0 & 0 & 200 & 77 & 33 & 21 & 16 & 57 & 8 & 12 \\
Rock wall & 75 & 0 & 0 & 205 & 239 & 3 & 3 & 86 & 0 & 0 \\
Clay ravine & 0 & 0 & 0 & 0 & 0 & 0 & 0 & 0 & 0 & 0 \\
Gorge & 8 & 0 & 2 & 3 & 17 & 124 & 58 & 63 & 3 & 0 \\
\hline
\end{tabular}


The mapped habitats constitute an overview of the distribution of important forest habitats for biodiversity within the municipalities. We utilised habitat maps from 10 municipalities within south-eastern Norway (Figure 1) with an overall number of 9470 mapped habitat units (Table 1). These 10 municipalities were selected because they (a) represented different parts of the major forestry region of Norway (Figure 1); and (b) because the maps and data files from these municipalities had a high quality, and therefore reduced the need for data preparation. According to Moen [17], two municipalities are situated in the southern boreal vegetation zone (Aurskog-Høland and Ullensaker), three in the boreo-nemoral zone (Marnardal, Songdalen, and Søgne), and five in the intermediate or northern boreal zone (Etnedal, Sør-Aurdal, Tokke, Rendalen, and Vinje). A summary of basic statistics for each municipality is given in Table 2. The data set constitutes a total study area of $2934 \mathrm{~km}^{2}$, representing the regional extent of south-east Norway (the most important forest region of Norway). An overall area of $81 \mathrm{~km}^{2}$ was classified as targeted $\mathrm{CHI}$ habitats. The habitat units thus constituted approximately $2.8 \%$ of the productive forest area. Figure 2 gives an example of mapped habitats from a municipality.

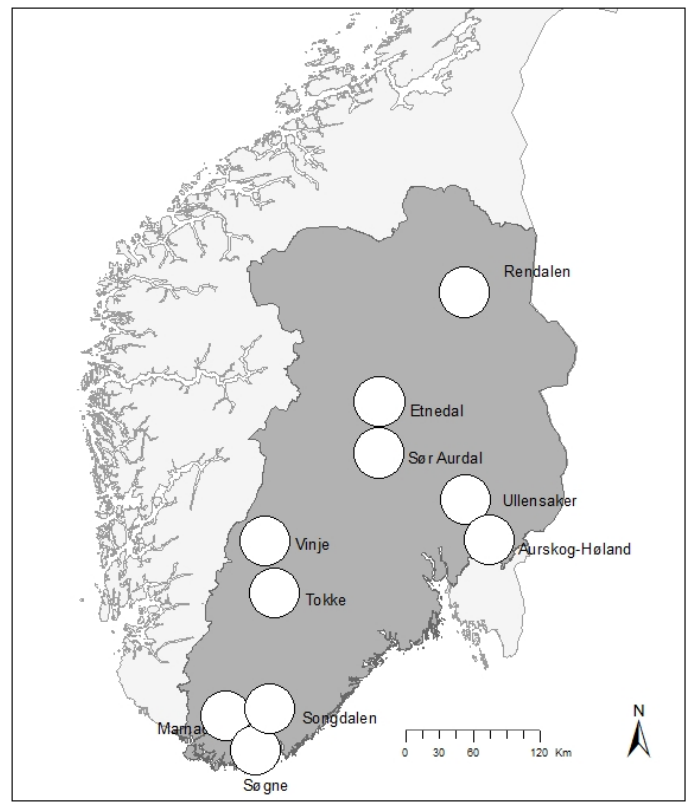

Figure 1. The 10 study areas (municipalities) in southern Norway included in this study: Rendalen, Etnedal, Sør-Aurdal, Ullensaker, Aurskog-Høland, Vinje, Tokke, Marnardal, Songdalen, and Søgne. The dark grey area constitutes the main forestry region of Norway.

Table 2. Area data for the 10 study areas (municipalities) included in this study. masl = metres above sea level.

\begin{tabular}{cccccc}
\hline Municipality & $\begin{array}{c}\text { Investigated } \\
\left.\text { Area } \mathbf{( k m}^{\mathbf{2}}\right)\end{array}$ & $\begin{array}{c}\text { Area of CHI } \\
\text { Habitat } \mathbf{( k m}^{\mathbf{2}} \mathbf{)}\end{array}$ & $\begin{array}{c}\text { Number of } \\
\text { CHI Habitats }\end{array}$ & $\begin{array}{c}\text { Lowest } \\
\text { Altitude (masl) }\end{array}$ & $\begin{array}{c}\text { Highest } \\
\text { Altitude (masl) }\end{array}$ \\
\hline Aurskog-Høland & 619 & 12 & 1023 & 111 & 391 \\
Ullensaker & 103 & 1 & 84 & 114 & 302 \\
Marnardal & 293 & 4 & 1364 & 17 & 502 \\
Songdalen & 152 & 5 & 930 & 0 & 405 \\
Søgne & 103 & 3 & 1068 & 0 & 263 \\
Etnedal & 259 & 5 & 733 & 213 & 1024 \\
Sør-Aurdal & 618 & 15 & 1518 & 153 & 1034 \\
Tokke & 280 & 15 & 1538 & 12 & 958 \\
Rendalen & 299 & 7 & 618 & 232 & 941 \\
Vinje & 208 & 14 & 594 & 183 & 968 \\
Sum & 2934 & 81 & 9470 & & \\
\hline
\end{tabular}



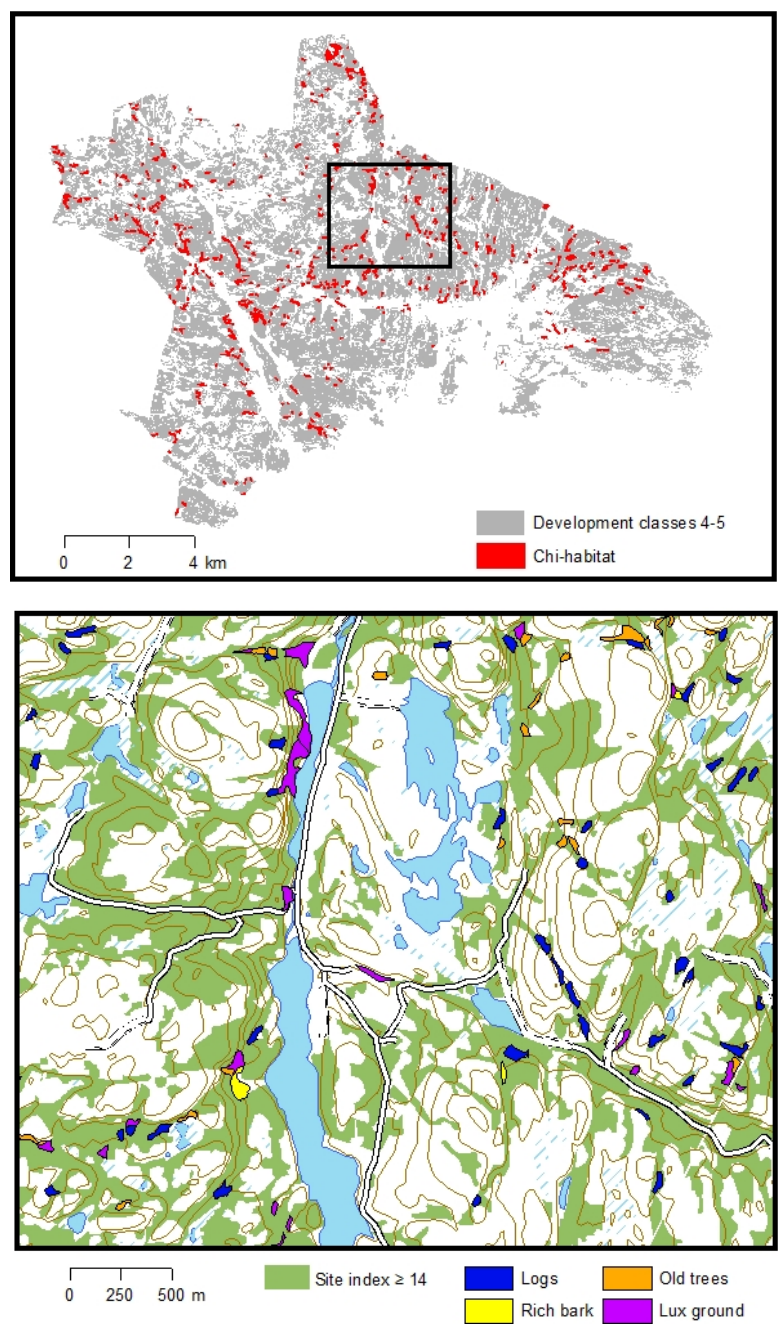

Figure 2. An example (from Søgne municipality) of a typical distribution of mapped CHI habitats within a landscape.

Digitised maps were used to investigate the distribution of the habitats in relation to the four landscape variables, and all GIS analyses were performed with ArcMap 10.0 [18]. We created a DEM (digital elevation model) by interpolating the surface using Spatial Analyst [18]. The DEM was used to derive a slope raster in percent. For each forest stand and habitat unit, we calculated a mean value of slope, elevation (altitude) and site index. In addition, a centre point was defined for each forest stand and habitat unit that was used to calculate the distance from the nearest road suitable for timber transport. Site index is estimated for each forest stand in the field by forest planners as the potential productivity, which is expressed as the value "H40 index", indicating the height of 40-year old trees [19]. Reference age of 40 years is the standard reference in the Nordic countries.

\subsection{Analyses}

First, to assess the spatial distribution of the $\mathrm{CHI}$ habitats we treated the observations as point patterns calculating the Ripley's K [20]. As the CHI habitats are mapped within development classes 4-5, they are bound by the distribution of forest stands of these development classes. The distribution of the Ripley's K was obtained from 1000 sets of random points within development classes 4-5, each of equal number to the CHI habitat in focus. If the observed Ripley's K exceeded the $97.5 \%$ percentile of the random distribution we infered a degree of aggregation of the CHI habitats that exceeded the spatial aggregation of the forest stand of development classes $4-5$. 
Furthermore, we compared landscape characteristics (slope, site index, altitude, distance to road) of defined habitat types [16] to those of (1) all productive forest stands (production potential $>1 \mathrm{~m}^{3} /$ hectare/year) of the municipalities; and (2) the mature part of the productive forest only (development class 5). A stand may include one or more habitat units, and a habitat unit may cross several stands. For each of the 10 municipalities, we focused on the deviations of the recorded habitat units by introducing a treatment contrast with all stands and mature stands as controls, respectively.

The Bayesian inference [21] applied followed a Generalized Linear Model setting where we assumed different likelihood functions for the various responses, Gaussian (altitude), Gamma (distance to road and slope), and negative binomial (site index), with corresponding mean to linear predictor link-functions, identity (Gaussian) and $\log$ (Gamma and negative binomial). Further, we specified all priors of the linear predictors being weak Gaussian distribution, i.e., Gaussian Latent Models. The linear predictors were similar across the responses with an intercept (stands) and effects representing the difference in each of the $\mathrm{CHI}$ habitats, i.e., a treatment-contrast specification. We assessed whether the $95 \%$ credibility interval for the effects of $\mathrm{CHI}$ habitats included 0, i.e., no difference among all forest stands. In this study, we used an Integrated Nested Laplace Approximation [22], a fast deterministic alternative to the simulation approach by MCMC algorithms [23]. The calculations were all performed using the software R [24].

\section{Results}

The number of habitat units recorded varied strongly among municipalities and habitat types (Table 1). One habitat type (Clay ravine) was not recorded in any of the municipalities, and two other habitat types (Hollow deciduous trees and Recently burned forest) were excluded because recorded units did not exceed 10 in any of the municipalities. Furthermore, Rock wall and Stream gorge were excluded because they are topographically defined habitat types and their qualities defined by presence of other $\mathrm{CHI}$ habitat types. Results from the analyses are presented for the remaining seven habitat types, or for the five most abundant habitats excluding Snags and Trees with pendant lichens which were present in small numbers only in several municipalities.

\subsection{Spatial Clustering}

The results from all the Ripley K analyses are shown in the Appendix. In Table 3, a summary is given of the proportion of investigated municipalities where the different habitat units were found to be more clustered than random. This proportion decreased as the scale increased. Whereas the proportion of significantly clustered outcomes was 0.96 at the shortest distance (up to $1 \mathrm{~km}$ ), it decreased gradually to 0.50 at the longest distance $(7.1-8.0 \mathrm{~km})$. Thus, generally we found that spatial clustering was high and most pronounced at shorter distances.

Table 3. Clustering of the most common habitats at different spatial scales, expressed as the proportion of investigated municipalities where the habitat units appeared more clustered than random according to a Ripley K analysis (see the Appendix). The sum row shows calculated proportion when adding clustered outcomes for all habitats and dividing by the total number of outcomes. Late succ = Late succession of deciduous trees, Lux ground = Luxuriant ground vegetation, Rich bark = Trees with nutrient-rich bark.

\begin{tabular}{ccccccccc}
\hline \multicolumn{7}{c}{ Distance $\mathbf{( k m )}$} \\
\hline Habitat & $\mathbf{0 - 1 . 0}$ & $\mathbf{1 . 1 - 2 . 0}$ & $\mathbf{2 . 1 - 3 . 0}$ & $\mathbf{3 . 1 - 4 . 0}$ & $\mathbf{4 . 1 - 5 . 0}$ & $\mathbf{5 . 1 - 6 . 0}$ & $\mathbf{6 . 1 - 7 . 0}$ & $\mathbf{7 . 1 - 8 . 0}$ \\
\hline Logs & $9 / 10$ & $9 / 10$ & $8 / 10$ & $8 / 9$ & $6 / 7$ & $4 / 5$ & $3 / 4$ & $1 / 2$ \\
Late succ & $10 / 10$ & $9 / 10$ & $7 / 10$ & $7 / 9$ & $5 / 8$ & $3 / 3$ & $2 / 2$ & $2 / 2$ \\
Old trees & $8 / 9$ & $8 / 9$ & $8 / 9$ & $5 / 8$ & $4 / 6$ & $2 / 5$ & $2 / 4$ & $1 / 3$ \\
Lux ground & $10 / 10$ & $9 / 10$ & $8 / 10$ & $7 / 9$ & $6 / 8$ & $4 / 6$ & $1 / 4$ & $0 / 1$ \\
\hline Rich bark & $8 / 8$ & $5 / 8$ & $4 / 8$ & $3 / 6$ & $3 / 4$ & $1 / 2$ & $0 / 1$ & - \\
Sum & 0.96 & 0.85 & 0.74 & 0.73 & 0.73 & 0.67 & 0.53 & 0.50 \\
\hline
\end{tabular}




\subsection{Slope}

The numbers of municipalities where different habitat types were found to be in flatter, steeper, or slopes that were not significantly different from all forest stands are summarized in Table 4 . Overall, only two out of a total of 53 statistical tests of habitat distribution within a municipality were found to occur in flatter terrain than expected. These two cases were Snags in one municipality and Pendant lichens in another. Generally, there was a strong overrepresentation of mapped habitats in steep terrain ( 40 out of 53 possibilities). This pattern is most pronounced for the habitat types Logs, Trees with nutrient-rich bark, Late succession of deciduous trees, Old trees, and Luxuriant ground vegetation. When the distribution of habitats was compared to mature forest only, the patterns were slightly weakened, but still with a clear tendency for the mapped habitats to be found in steeper terrain than expected (35 out of 51 statistical tests). None of the habitat types were found to occur in flatter terrain than expected within mature forest (Table 4).

Table 4. Differences in the distribution of $\mathrm{CHI}$ habitats compared to all forest and all mature forest, respectively, for the variables slope, site index, altitude, and distance from road. The numbers refer to the number of municipalities with statistically significant outcomes $(p<0.05)$, and those not significantly different (NS) from random expectation (see Supplementary material for Bayesian tests for each municipality and habitat type). The number of outcomes varies between habitat types because not all habitats were found in all municipalities. Late succ $=$ Late succession of deciduous trees, Pend lichen = Pendant lichens, Lux ground = Luxuriant ground vegetation, Rich bark = Trees with nutrient-rich bark.

\begin{tabular}{|c|c|c|c|c|c|c|c|c|c|c|c|c|}
\hline \multirow{2}{*}{ CHI hab } & \multicolumn{3}{|c|}{ Slope } & \multicolumn{3}{|c|}{ Site Index } & \multicolumn{3}{|c|}{ Altitude } & \multicolumn{3}{|c|}{ Distance from Road } \\
\hline & Flatter & NS & Steeper & Lower & NS & Higher & Lower & NS & Higher & Shorter & NS & Longer \\
\hline \multicolumn{13}{|l|}{ All Forest } \\
\hline Snags & 1 & 0 & 3 & 0 & 3 & 1 & 0 & 3 & 1 & 0 & 2 & 2 \\
\hline $\log s$ & 0 & 1 & 9 & 0 & 1 & 9 & 6 & 2 & 2 & 0 & 0 & 10 \\
\hline Late succ & 0 & 3 & 7 & 0 & 0 & 10 & 7 & 2 & 1 & 3 & 6 & 1 \\
\hline Lux ground & 0 & 2 & 8 & 0 & 0 & 10 & 9 & 0 & 1 & 3 & 6 & 1 \\
\hline Rich bark & 0 & 1 & 6 & 0 & 2 & 5 & 4 & 3 & 0 & 0 & 7 & 0 \\
\hline Total & 2 & 11 & 40 & 6 & 8 & 39 & 28 & 11 & 14 & 6 & 23 & 24 \\
\hline \multicolumn{13}{|l|}{ Mature Forest } \\
\hline Old trees & 0 & 2 & 7 & 4 & 1 & 4 & 2 & 3 & 4 & 1 & 2 & 6 \\
\hline Lux ground & 0 & 2 & 8 & 0 & 1 & 9 & 7 & 3 & 0 & 5 & 4 & 1 \\
\hline Rich bark & 0 & 2 & 4 & 0 & 2 & 4 & 3 & 3 & 0 & 1 & 5 & 0 \\
\hline Total & 0 & 16 & 35 & 4 & 9 & 38 & 26 & 18 & 7 & 13 & 22 & 16 \\
\hline
\end{tabular}

\subsection{Site Index}

Overall, there was a clear tendency for the different habitats to be found at a higher site index than expected. This was not only the case for nutritious habitat types such as Trees with nutrient-rich bark (five out of seven possible) and Luxuriant ground vegetation (10 out of 10), but also for Logs (nine out of 10) and Late succession of deciduous trees (10 out of 10). In fact, 39 out of 53 comparisons turned out to be at a significantly higher site index (Table 4). Only six out of 53 tests across municipalities showed statistical overrepresentation at lower site index than expected from all forest stands. Interestingly, the habitat type Old trees constitutes five of these. When comparing with mature forest only, the positive effect of site index was even clearer, and now also Snags were found to be more often located in stands with higher site index (Table 4). 


\subsection{Altitude}

Out of the 53 comparisons 28 showed a statistical overrepresentation of habitats at a lower altitude than expected. This pattern was most pronounced for Logs (six out of 10), Late succession of deciduous trees (seven out of 10), and Luxuriant ground vegetation (nine out of 10). Only one type of habitat was generally found at a higher altitude than expected, namely Old trees (seven out of nine). Restricting the comparisons to mature forest only, gave a similar result regarding the general affinity of the habitats to lower altitudes, but Old trees were still more often found at higher altitudes (Table 4).

\subsection{Distance from Road}

With respect to distance from road, 24 out of 53 comparisons showed significantly longer distances from road for recorded habitats, whereas six showed shorter distances, compared to random expectation. When compared to mature forests, the overall clear effect of distance from road was lost (16 comparisons in favour of longer distances, 13 comparisons in favour of shorter distances, and 22 not significantly different). This was because Late successions of deciduous trees, Luxuriant ground vegetation, and Trees with nutrient-rich bark within mature forest were together clearly overrepresented at shorter distances from road, combined with a less clear pattern of overrepresentation of Logs at longer distances from road (Table 4).

\section{Discussion}

\subsection{Habitat Distribution Patterns}

This is the first study investigating the spatial distribution of WKHs in forest landscapes. The Ripley's K analyses showed that there was a general pattern of aggregated spatial distribution of $\mathrm{CHI}$ habitats within productive forest in development classes $4-5$. This was especially the case at distances up to a few kilometres. To study potential causes for this pattern, we investigated the relationship between the distribution of the various $\mathrm{CHI}$ habitats and four key landscape features, namely, slope, site index, altitude, and distance from road. All CHI habitats that showed significant patterns across municipalities were overrepresented on steep slopes and at high site index, when compared with all productive forest stands. Furthermore, all habitat types were overrepresented at low altitude, except Old trees (Table 4). When comparing the habitat types with mature forest only, two main patterns appeared regarding distance from road: (1) habitats rich in deciduous trees were overrepresented at shorter distance from road than expected; and (2) old-growth habitats were overrepresented at longer distance from road than expected.

In this study, we have investigated the spatial distribution of important forest habitats for red-listed forest species, not the distribution of the species living in these habitats as such. It is therefore a study of the amount or density of important habitats, primarily for species groups such as insects and fungi. These two species groups constitute $80 \%$ of all forest living red-listed species in Norway. We argue that information about habitat density along gradients should be included as one important variable in order to understand biodiversity distributions along altitudinal gradients. This is especially important for species groups that are linked to specific habitats, such as fungi and insects living in dead wood.

There are two main spatio-temporal factors contributing to the distribution of habitats in landscapes: Environmental factors and human impact factors. These factors have interacted historically in shaping the present forest landscapes. We suggest that the patterns we have identified in our study system may represent general patterns of spatial distribution of important small-scale areas for forest biodiversity. Below we discuss how environmental factors and forestry can explain the distribution of $\mathrm{CHI}$ habitats in Norwegian forest landscapes. 


\subsection{Environmental Factors}

Why are the recorded habitats overrepresented in steep terrain? We suggest that there are at least three environmental factors (not mutually exclusive) contributing to this pattern. First, steep slopes will have a higher level of disturbance such as screes and avalanches. This will in turn increase the mortality rate of trees and favour the creation of habitats such as Logs and the recruitment of deciduous trees (eventually developing into Late succession of deciduous trees and Trees with nutrient-rich bark). One disturbance factor may be of particular importance for the present distribution of logs in the investigated region of Norway, and that is a massive bark beetle (Ips typographus) outbreak in the 1970s, that killed a particularly high number of spruce trees situated on high site index on slopes at lower altitudes [25].

Second, steep slopes have on average a higher productivity. Grant [26] found that slope positions had a higher net primary productivity than flatter basin areas as a result of lower soil water contents, higher soil temperatures, and more rapid oxygen uptake which accelerated nutrient mineralization and uptake. Furthermore, Laamrani et al. [27] found a positive correlation between slope and site index across spatial resolutions from 5 to 20 metres in black spruce boreal forest in Canada. In our 10 municipalities, there was a weak but consistent positive correlation between slope and site index (mean: $r=0.20$ ). Finally, southerly exposed slopes and hillsides will experience a higher summer temperature and therefore support more thermophilous species generally associated with the habitat Luxuriant ground vegetation in boreal forests [17].

All habitat types that were associated with steep terrain, except Old trees, were consistently overrepresented at a higher site index and a lower altitude than expected. Habitat types such as Nutrient rich bark, Late succession of deciduous trees, and Luxuriant ground vegetation were all directly related to a high site index. Generally, productivity increases with increasing temperature (e.g., [28]). In Fennoscandia, July mean temperature decreases with approximately 0.57 degrees Celsius /100 metre altitudinal increase [29] and productivity therefore decreases with increasing altitude. In the investigated municipalities, the correlation between site index and altitude was on average $r=-0.43$. Interestingly, we found that old-growth habitats like Snags and Logs were also overrepresented at high site index. We suggest that this pattern is an indirect effect of high productivity. Basal area of standing trees increases with productivity (e.g., [30]), and so does the amount of dead wood in old-growth forests [31]. Because high-productive sites (usually at lower altitudes) have a higher growth rate, these sites will produce old-growth characteristics, such as large volume of dead wood, faster than low-productive sites (more common at higher altitudes). In the future, more low-productive sites at high altitudes will have had time to develop corresponding volumes of dead wood.

Pendant lichens and Snags did not show a clear pattern in relation to altitude within each municipality, but they were both strongly associated with elevated municipalities. At present, we are not able to explain the distribution of these habitat types, although we suggest that the prevalence of Snags in municipalities at higher elevation may be related to increased mortality of trees due to heavy snow load, and a higher longevity (and accumulation) of snags at lower temperature.

The habitat Old trees stands out as an exception to the general pattern of overrepresentation at high site index at lower altitude. This may simply reflect a relationship between tree age longevity and productivity; that trees generally get older at low site index as a result of slow growth [32]. However, this may also reflect a higher level of harvesting at the more lucrative areas of high site index in the past, and serves as an example of how environmental factors and human impact may interact to determine the spatial distribution of habitats.

\subsection{The Impact of Forestry}

Historically, the harvesting practice in Norwegian forests was dimension felling (i.e., selective logging of large-diameter trees). Virtually all productive forest area in Norway has been selectively logged during the past centuries. As a result of this, dead wood and old trees became scarce, dead wood probably reaching a historically low level in the first half of the twentieth century [33]. However, 
modern forestry practices, including clear-felling of whole stands and subsequent afforestation with seeding or planting, replaced selective logging around the middle of the twentieth century (e.g., [34,35]). After this shift, the volume of dead wood has increased [15]. The reason for this is that large areas of forests that are not yet harvested by clear-felling have barely been harvested at all since the introduction of stand-replacing forestry. Time since last logging in these forests typically varies from 50 to 150 years. Today, these stands are predominantly classified as development class 5 (mature forest). Most of the regenerating stands from clearcuttings, on the other hand, have not had the time to develop maturity and typical old-growth habitats.

Almost all mapped habitats were (by definition) situated in mature forests. By changing the comparison from all forest stands to mature stands only, we were able to evaluate the effect of stand-replacing forestry on the distribution of $\mathrm{CHI}$ habitats in landscapes. We found that the habitats were overrepresented in steep terrain when comparing with all development classes in productive forest. This could be interpreted as a result of the more recent harvesting history. Modern forestry is dependent on harvesters and forwarders which are most efficient in easily accessible terrain. It is therefore to be expected that stands regenerating from clear-felling will be underrepresented in steep and demanding terrain and overrepresented in flatter terrain, and vice versa we would expect that habitats in mature forest would be overrepresented in steep terrain. However, we found the same pattern when we limited our comparison to habitats within mature forest only. This is an important finding because overrepresentation within mature forest will have to be explained by factors other than stand-replacing forestry carried out during the last 60-70 years.

We are not aware of any studies which have investigated whether past harvesting rate by selective logging has been lower in steep terrain compared to flatter terrain. However, this was indicated by the overrepresentation of Logs in steep terrain within mature forest. The same can be seen for Old trees, especially in the three municipalities in the boreo-nemoral zone. The remaining two old-growth habitats Pendant lichens and Snags, however, did not show any overrepresentation in steep terrain. It is therefore unclear whether long-term logging has affected the present distribution of habitats in relation to steep terrain. Further studies are needed to separate the effects of harvesting from the effects of productivity on the spatial distribution of habitats with regard to terrain steepness.

Interestingly, the only habitat types being overrepresented in areas more distant from roads than expected were Logs, Old trees, and Pendant lichens. These are all considered old-growth habitats [16]. This pattern was also clear within mature forest only, and we suggest that it may reflect long-term harvesting patterns related to terrain transport distances. In contrast, the habitats associated with high productivity, such as Late succession of deciduous trees and Luxuriant ground vegetation, were often found closer to roads than expected. This may reflect the correlation between distance from road and altitude $(r=0.29)$, combined with a higher level of general human influence in lowland areas. Main forest roads in Norway typically follow the bottoms of the valleys where we find areas that are easily accessible with the most economically valuable forest. As a result, former human influence such as grazing by domestic animals, summer farming, and firewood harvesting has also been most pronounced in these easily accessible parts of the landscape. After being abandoned, many of these areas have been colonized by deciduous forest.

\subsection{Management Considerations}

One of the most striking results of this study is the consistent overrepresentation of $\mathrm{CHI}$ habitats in steep terrain. As can be seen from Figure 3, the habitats are clearly underrepresented in flat terrain ( $0 \%-19 \%$ slope), and overrepresented in steep terrain (slopes above $33 \%)$. In steep terrain, cable yarding operations are most often used in Norway. However, net profit from cable yarding operations is usually small, and harvesting in these areas has therefore been uncommon. Approximately $70 \%$ of the $\mathrm{CHI}$ habitats have been selected to be set aside as woodland key habitat (WKH) and managed for biological diversity. As we can see from Figure 3, these selected WKHs are even more overrepresented in slopes above $50 \%$ than in the total list of all mapped habitats. We can therefore conclude that where 
habitat inventories have been carried out, the current WKHs set aside are well represented in steep slopes with high biodiversity values.

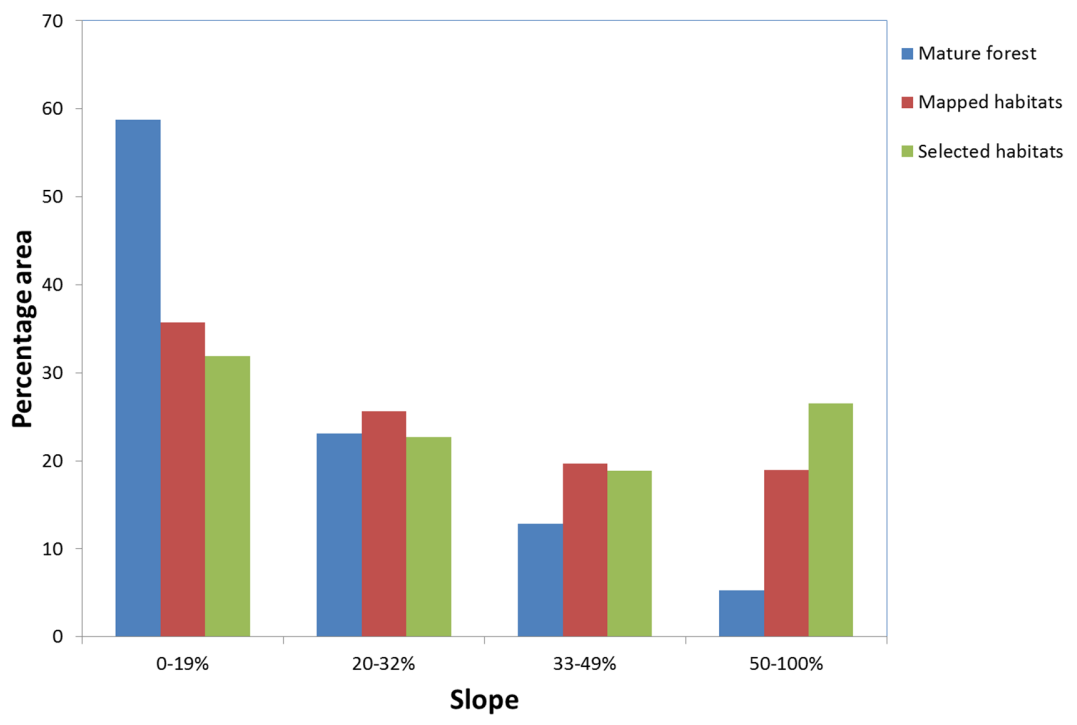

Figure 3. Percentage area of mature forest (development class 5), mapped CHI habitats, and selected $\mathrm{CHI}$ habitats in different classes of slope.

Few studies have investigated the efficiency of $\mathrm{CHI}$ habitats in maintaining species diversity. However, Gjerde et al. [16] compared the density of red-listed species in CHI habitats (Logs and Trees with nutrient rich bark) with that in randomly selected old-growth forest. They found the density to be four times higher in CHI habitats. Furthermore, Sverdrup-Thygeson et al. [36] found that CHI habitats had a high species richness of old-growth fungi on spruce logs and beetles in early-decay aspen snags. Although they found some differences in species composition between nature reserves and $\mathrm{CHI}$ habitats, they concluded that $\mathrm{CHI}$ habitats constitute an important complementary function in maintaining species diversity in combination with nature reserves and retention patches. However, no studies have investigated to what extent $\mathrm{CHI}$ habitats maintain long term species diversity.

The most cost-effective areas to harvest in steep terrain would be areas with high site index at low altitudes. These are exactly the parts of the forests landscapes we have identified as having particularly high occurrence of habitats important for biodiversity. Today, habitat inventories in steep terrain are often insufficient or lacking, and are both expensive and time consuming to carry out. Thus, there is a need for studies developing more effective habitat inventories which can increase the quality and cost-effectiveness of habitat mapping, particularly in steep terrain.

Table 5. The proportion (\%) of investigated area (development classes 4 and 5) consisting of different habitat types, and the proportion of the same habitat types on the $25 \%$ steepest slopes, lowest altitudes, highest site index, and longest distance from road. The numbers in parentheses are the ratio between a given entry and that of all investigated forest, i.e., number of times higher cover of a habitat type. The highest value for each variable is denoted in bold. Late succ = Late succession of deciduous trees, Lux ground = Luxuriant ground vegetation, Rich bark = Trees with nutrient-rich bark.

\begin{tabular}{cccccc}
\hline Habitat & $\begin{array}{c}\text { All forest } \\
\text { Investigated }\end{array}$ & Steep Slopes & $\begin{array}{c}\text { Low } \\
\text { Altitudes }\end{array}$ & $\begin{array}{c}\text { High Site } \\
\text { Index }\end{array}$ & $\begin{array}{c}\text { Long Distance } \\
\text { from Road }\end{array}$ \\
\hline Logs & 0.85 & $2.01(2.36)$ & $1.43(1.68)$ & $2.08(2.45)$ & $0.88(1.03)$ \\
Late succ & 0.31 & $0.66(2.14)$ & $0.64(2.05)$ & $0.91(2.93)$ & $0.20(0.63)$ \\
Old trees & 1.42 & $2.50(1.76)$ & $0.87(0.61)$ & $1.08(0.76)$ & $2.83(\mathbf{1 . 9 9 )}$ \\
Lux ground & 1.19 & $3.19(2.68)$ & $3.12(2.62)$ & $4.08(3.43)$ & $0.56(0.47)$ \\
Rich bark & 0.12 & $0.36(\mathbf{3 . 0 2})$ & $0.32(\mathbf{2 . 6 5 )}$ & $0.35(2.92)$ & $0.08(0.66)$ \\
\hline
\end{tabular}


Generally, we found that the various habitat types are approximately two to three times as common in the $25 \%$ steepest slopes, lowest altitudes, and highest site indices (Table 5). We suggest that this level of overrepresentation is a good starting point to develop more efficient inventory methods. Few studies have investigated the cost of WKHs, and these have either investigated direct loss of forest revenues (e.g., [37]), or estimated indirect costs such as terrain transportation costs when WKHs impose limitations to optimal extraction trails in the area [38]. We recommend that new studies investigate how to develop more effective habitat inventories to meet the need in steep terrain in areas where habitat mapping has not yet been conducted. The use of airborne laser scanning (e.g., [39]) combined with more targeted field inventories seems to represent an especially promising approach in this respect.

Acknowledgments: This study was financed by the Research Council of Norway's projects "Greenwood" and "Bionær", and the Norwegian Ministry of Food and Agriculture. We also thank Nicholas Clarke for correcting the English.

Author Contributions: Magne Sætersdal and Ivar Gjerde conceived and designed the study, and were the main authors of the manuscript. Einar Heegaard, Fride Schei and Jan Erik Nilsen prepared and/or performed the GIS and/or statistical analyses, and contributed in writing the manuscript.

Conflicts of Interest: The authors declare no conflicts of interest.

\section{References}

1. FAO. Global Forest Resources Assessment 2010. In FAO Forestry Paper; Food and Agricultural Organisation of the United Nations: Rome, Italy, 2010.

2. CPF. Strategic Framework for Forests and Climate Change. In A proposal by the Collaborative Partnership on Forests for a Coordinated Forest-sector Response to Climate Change; The Collaborative Partnership on Forests: Bali, Indonesia, 2008.

3. Lindenmayer, D.B.; Franklin, J.F.; Lõhmus, A.; Baker, S.C.; Bauhus, J.; Beese, W.; Brodie, A.; Kiehl, B.; Kouki, J.; Pasture, G.M.; et al. A major shift to the retention approach for forestry can help resolve some global forest sustainability issues. Cons. Lett. 2012, 5, 421-431. [CrossRef]

4. Grau, O.; Grytnes, J.-A.; Birks, H.J.B. A comparison of altitudinal species richness patterns of bryophytes with other plant groups in Nepal, Central Himalaya. J. Biogeogr. 2007, 34, 1907-1915. [CrossRef]

5. Rahbek, C. The role of spatial scale and the perception of large-scale species-richness patterns. Ecol. Lett. 2005, 8, 224-239. [CrossRef]

6. Körner, C. Mountain biodiversity, its causes and function: An overview. In Mountain Biodiversity: A Global Assessment; Körner, C., Spehn, E.M., Eds.; Parthenon: Boca Raton, FL, USA, 2002; pp. 3-20.

7. Grytnes, J.-A.; Heegaard, E.; Ihlen, P.G. Species richness of vascular plants, bryophytes, and lichens along an altitudinal gradient in western Norway. Acta Oecol. Int. J. Ecol. 2006, 29, 241-246. [CrossRef]

8. Field, R.; Hawkins, B.A.; Cornell, H.V.; Currie, D.J.; Diniz-Filho, J.A.F.; Guegan, J.-F.; Kaufman, D.M.; Kerr, J.T.; Mittelbach, G.G.; Oberdorff, T.; et al. Spatial species-richness gradients across scales: A meta-analysis. J. Biogeogr. 2009, 36, 132-147. [CrossRef]

9. Whittaker, R.J.; Willis, K.J.; Field, R. Scale and species richness: Towards a general hierarchical theory of species diversity. J. Biogeogr. 2001, 28, 453-470. [CrossRef]

10. Gjerde, I.; Sætersdal, M.; Rolstad, J.; Storaunet, K.O.; Blom, H.H.; Gundersen, V.; Heegaard, E. Productivity-diversity relationships for plants, bryophytes, lichens, and polypore fungi in six northern forest landscapes. Ecography 2005, 28, 705-720. [CrossRef]

11. Connell, J.H. Diversity in tropical rain forests and coral reefs: High diversity of trees and corals is maintained only in a non-equilibrium state. Science 1978, 199, 1302-1310. [CrossRef] [PubMed]

12. Lindenmayer, D.B.; Franklin, J.F. Conserving Forest Biodiversity; Island Press: Washington, DC, USA, 2002.

13. Franklin, J.F.; Berg, D.E.; Thornburgh, D.A.; Tappeiner, J.C. Alternative silvicultural approaches to timber harvest: Variable retention harvest systems. In Creating a Forestry for the 21st Century; Kohm, K.A., Franklin, J.F., Eds.; Island Press: Covelo, CA, USA, 1997; pp. 111-139. 
14. Timonen, J.; Siitonen, J.; Gustafsson, L.; Kotiaho, J.S.; Stokland, J.N.; Sverdrup-Thygeson, A.; Mönkkönen, M. Woodland key habitats in northern Europe: Concepts, inventory and protection. Scand. J. For. Res. 2010, 25, 309-324. [CrossRef]

15. Granhus, A.; Hylen, G.; Nilsen, J.-E. Statistics of forest conditions and resources in Norway. Ressursoversikt fra Skog og Landskap 2012, 3, 1-85.

16. Gjerde, I.; Sætersdal, M.; Blom, H.H. Complementary Hotspot Inventory-A method for identification of important areas for biodiversity at the forest stand level. Biol. Conserv. 2007, 137, 549-557. [CrossRef]

17. Moen, A. National Atlas of Norway: Vegetation; Norwegian Mapping Authority: Hønefoss, Norway, 1999.

18. ESRI. ArcMap: Release 10.0; Environmental Systems Research Institute: Redlands, CA, USA, 2013.

19. Tveite, B.; Braastad, H. Bonitering av gran, furu og bjørk. Nor. Skogbr. 1981, 27, 17-22.

20. Cressie, N.A.C. Statistics for Spatial Data Revised Edition; Wiley Series in Probability and Mathematical Statistics; John Wiley \& Sons: New York, NY, USA, 1993.

21. Gelman, A.; Carlin, J.; Stern, H.; Dunson, D.; Vehtari, A.; Rubin, D. Bayesian Data Analysis, 3rd ed.; Chapman \& Hall: London, UK, 2013.

22. Rue, H.; Martino, S.; Chopin, N. Bayesian inference for latent Gaussian models by using integrated nested Laplace approximations. J. R. Stat. Soc. 2009, 71, 319-392. [CrossRef]

23. Blangiardo, M.; Cameletti, M. Spatial and Spatio-Temporal Bayesian Models with R-INLA; John Wiley \& Sons: Chichester, UK, 2015.

24. R Core Team. R: A Language and Environment for Statistical Computing; Rversion 3.1.1.; R Foundation for Statistical Computing: Vienna, Austria, 2014.

25. Worrell, R. Damage by the spruce bark beetle in South Norway 1970-80: A survey, and factors affecting its occurrence. Rep. Nor. For. Res. Inst. 1983, 38, 1-34.

26. Grant, R.F. Modeling topographic effects on net ecosystem productivity of boreal black spruce forests. Tree Physiol. 2004, 24, 1-18. [CrossRef] [PubMed]

27. Laamrani, A.; Valeria, O.; Bergeron, Y.; Fenton, N.; Cheng, L.Z.; Anyomi, K. Effects of topography and thickness of organic layer on productivity of black spruce boreal forests of the Canadian Clay Belt region. For. Ecol. Manag. 2014, 330, 144-157. [CrossRef]

28. Anyomi, K.; Raulier, F.; Girardin, M.; Bergeron, Y. Using height growth to model local and regional response of trembling aspen (Populus tremuloides Michx.) to climate within the boreal forest of western Quebec. Ecol. Mod. 2012, 243, 123-132. [CrossRef]

29. Laaksonen, K. Areal distribution of monthly mean air temperatures in Fennoscandia (1921-1950). Fennia 1979, 157, 89-124.

30. Storaunet, K.O.; Rolstad, J.; Gjerde, I.; Gundersen, V.S. Historical logging, productivity, and structural characteristics of boreal coniferous forests in Norway. Silva Fenn. 2005, 39, 429-442. [CrossRef]

31. Sippola, A.-L.; Siitonen, J.; Kallio, R. Amount and quality of coarse woody debris in natural and managed coniferous forests near the timberline in Finnish Lapland. Scand. J. For. Res. 1998, 13, 204-214. [CrossRef]

32. Johnson, B.G.; Abrams, M.D. Age class, longevity and growth rate relationships: Protracted growth increases in old trees in eastern United States. Tree Physiol. 2009, 29, 1317-1328. [CrossRef] [PubMed]

33. Stokland, J.N.; Larsson, K.-H. Legacies from natural forest dynamics: Different effects of forest management on wood-inhabiting fungi in pine and spruce forests. For. Ecol. Manag. 2011, 261, 1707-1721. [CrossRef]

34. Braathe, P. The background of the transition to forest stand management. Tidsskr. Skogbruk 1980, 88, 143-148.

35. Jonsson, B.G.; Hofgaard, A. The structure and regeneration of high-altitude Norway spruce forests: A review of Arnborg (1942, 1943). Scand. J. For. Res. 2011, 26, 17-24. [CrossRef]

36. Sverdrup-Thygeson, A.; Bendiksen, E.; Birkemoe, T.; Larsson, K.H. Do conservation measures in forest work? A comparison of three area-based conservation tools for wood-living species in boreal forests. For. Ecol. Manag. 2014, 330, 8-16. [CrossRef]

37. Wikberg, S.; Perhans, K.; Kindstrand, C.; Djupström, L.B.; Boman, M.; Mattson, L.; Schroeder, L.M.; Weslien, J.; Gustafsson, L. Cost-effectiveness of conservation strategies implemented in boreal forests: The area selection process. Biol. Cons. 2009, 142, 614-624. [CrossRef] 
38. Søvde, N.E.; Sætersdal, M.; Løkketangen, A. A scenario-based method for assessing the impact of suggested woodland key habitats on forest harvesting costs. Forests 2014, 5, 2327-2344. [CrossRef]

39. Næsset, E. Airborne laser scanning as a method in operational forest inventory: Status of accuracy assessments accomplished in Scandinavia. Scand. J. For. Res. 2007, 22, 433-442. [CrossRef]

(c) 2016 by the authors; licensee MDPI, Basel, Switzerland. This article is an open access article distributed under the terms and conditions of the Creative Commons by Attribution (CC-BY) license (http:/ / creativecommons.org/licenses/by/4.0/). 